\title{
Intraperitoneal endoscopic salvage using an enteral stent for a misdeployed lumen- apposing metal stent during endoscopic ultrasound-guided gastroenterostomy
}
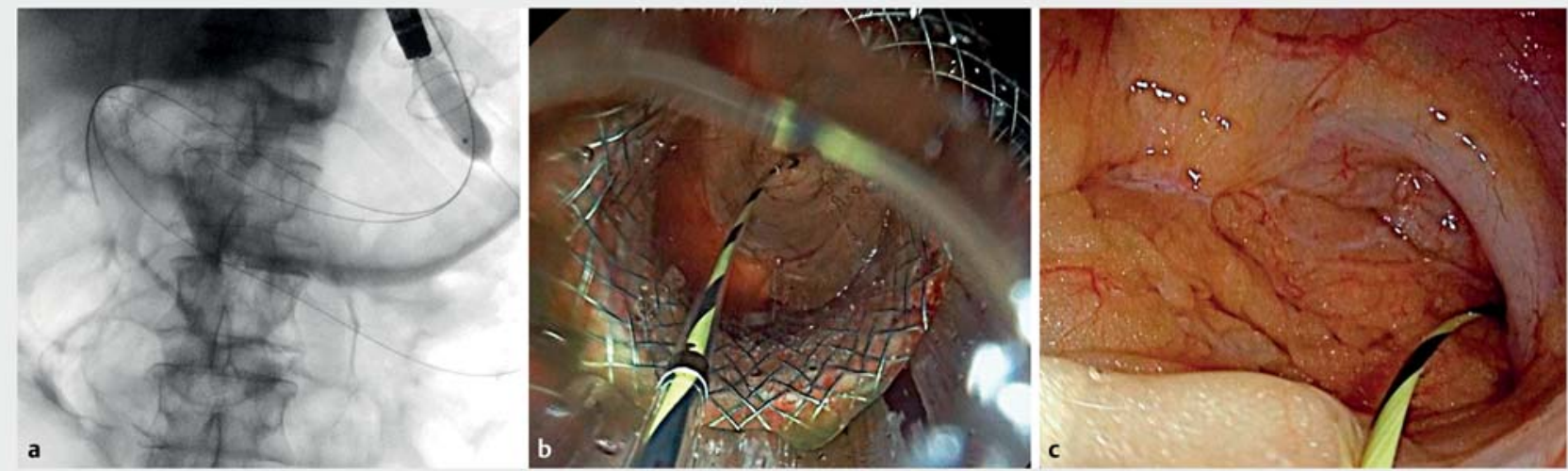

- Fig. 1 Images showing: a, b dilation of a misplaced lumen-apposing metal stent (LAMS) to allow the scope to be passed into the peritoneum; c peritonoscopy being performed through LAMS with the intention of identifying the point of entry of the guidewire inside the bowel.

A 57-year-old man with duodenal carcinoma and a biliary self-expandable metal stent (SEMS) presented with gastric outlet obstruction and an endoscopic ultrasound (EUS)-guided gastroenterostomy was proposed.

After the bowel had been dilated up to $15 \mathrm{~mm}$ to allow the gastroscope to be passed across the duodenum, loops of the small bowel were distended with $1 \mathrm{~L}$ of saline mixed with methylene blue, using the water-jet channel. A smallbowel loop was then accessed using the freehand technique with the delivery system of an electrocautery-enhanced lumen-apposing metal stent (LAMS; Hot AXIOS; $20 \times 10 \mathrm{~mm}$ ). During advancement of the preloaded guidewire, the bowel loop became tented away and the EUS window was lost, so the distal flange was deployed with concerns of possible misplacement. After deployment of the proximal flange, no flow of blue fluid was noted.

The peritoneal cavity was identified endoscopically through the LAMS and the echoendoscope was exchanged for a therapeutic gastroscope. The guidewire tip, located in the duodenum, was stretched to the outside with the purpose of stabilizing the bowel. Balloon expan-

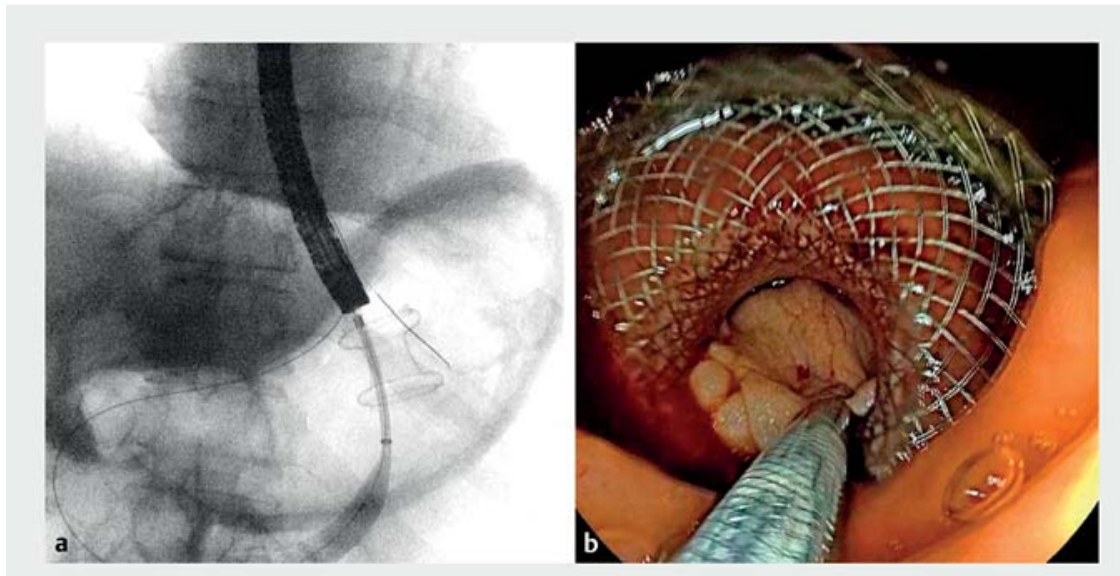

Fig. 2 Views of the enteral fully covered self-expandable metal stent deployed within the misplaced lumen-apposing stent to create a bridge between the small bowel and the stomach on: a fluoroscopy; b endoscopy.

sion of the LAMS up to $15 \mathrm{~mm}$ allowed the gastroscope to be passed into the peritoneal cavity using the LAMS as a trocar. Peritonoscopy was performed under fluoroscopy guidance and the entry point of the guidewire into the bowel was identified ( $>$ Fig.1). Dilation of the enteral wall up to $8 \mathrm{~mm}$ facilitated the advancement of a fully covered SEMS (Niti-S EnteralColonic; $20 \times 80 \mathrm{~mm}$; Taewoong Medical) through the LAMS. These tech- nical aspects prevented the risk of tenting away of the bowel loop and loss of the guidewire. Enterography confirmed that the enteral stent was well positioned though the misplaced LAMS, allowing a correct deployment of the rescue stent under fluoroscopy and endoscopy guidance ( $>$ Fig.2). Lastly, the distal end within the duodenum was checked, and an antimigratory clip was fixed ( $\triangleright$ Fig. 3; - Video 1). 


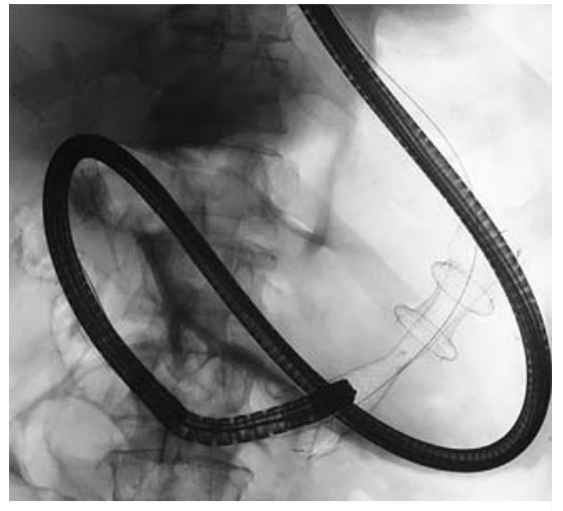

Fig. 3 Fluoroscopic image showing the distal end of the enteral stent being checked from the duodenum.

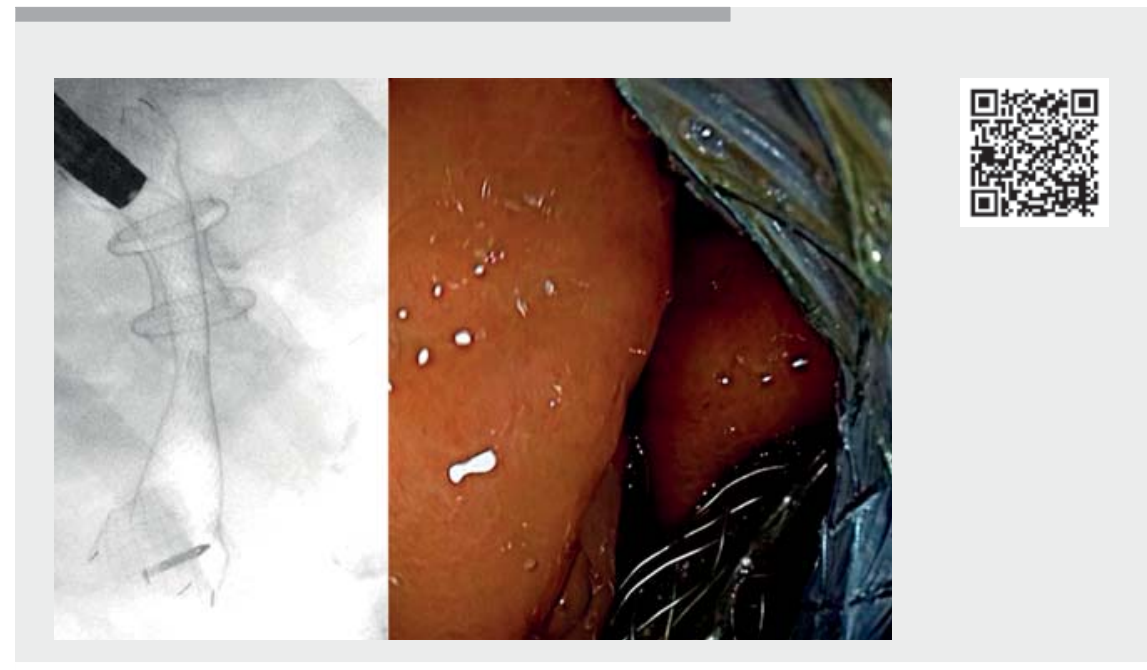

Video 1 Intraperitoneal endoscopic salvage using an enteral stent for a lumen-apposing metal stent that was misdeployed during the creation of an endoscopic ultrasoundguided gastroenterostomy.
Several rescue options have been previously presented for gastroenterostomy [1-5]. If the wire access to the target loop is not preserved, LAMS misdeployment can require natural orifice transluminal endoscopic surgery (NOTES) or conventional surgery. If the guidewire is secure, a second enteral SEMS can be deployed safely under peritonoscopy and fluoroscopy guidance.

Endoscopy_UCTN_Code_CPL_1AL_2AC

\section{Competing interests}

J. B. Gornals is a consultant for Boston Scientific. The remaining authors declare that they have no conflict of interest.

The authors

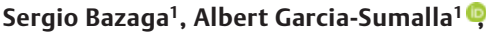
Berta Laquente ${ }^{2}$, Joan B. Gornals ${ }^{1,3}$

1 Endoscopy Unit, Department of Digestive Diseases, Hospital Universitari de Bellvitge, Bellvitge Biomedical Research Institute (IDIBELL), University of Barcelona, Spain

2 Medical Oncology Department, Institut Català d'Oncologia DiR, Bellvitge Biomedical Research Institute (IDIBELL), L'Hospitalet, Barcelona, Spain

3 Faculty of Health Sciences, Universitat Oberta de Catalunya, Barcelona, Spain
Corresponding author

\section{Joan B. Gornals, MD, PhD}

Endoscopy Unit, Dept. of Digestive Diseases, Hospital Universitari de Bellvitge - IDIBELL (Bellvitge Biomedical Research Institute), Feixa Llarga s/n, 08907 L'Hospitalet de Llobregat, Barcelona, Catalonia, Spain jgornals@bellvitgehospital.cat

\section{References}

[1] Tyberg A, Zerbo S, Barthet M et al. A novel technique for salvaging a dislodged lumenapposing metal stent during creation of an endoscopic gastrojejunostomy. Gastrointest Endosc 2016; 83: 254

[2] Sanchez-Ocana R, Penas-Herrero I, Gil-Simon $P$ et al. Natural orifice transluminal endoscopic surgery salvage of direct EUS-guided gastrojejunostomy. VideoGIE 2017; 2: 346348

[3] Ligresti D, Amata M, Barresi L et al. The lumen-apposing metal stent (LAMS)-in-LAMS technique as an intraprocedural rescue treatment during endoscopic ultrasoundguided gastroenterostomy. Endoscopy 2019; 51: 331-332

[4] James TW, Grimm IS, Baron TH. Intraperitoneal echoendoscopy for rescue of a gastrojejunal anastomosis. VideoGIE 2019; 4: 528529

[5] Abdelqader A, Nasr ]. Natural orifice transluminal endoscopic salvage of dislodged endoscopic ultrasound-guided jejunogastrostomy stent after endoscopic retrograde in Roux-en-Y anatomy. Am J Gastroenterol 2019; 114: 1024
Bibliography

Endoscopy 2022; 54: E232-E233

DOI 10.1055/a-1494-3055

ISSN $0013-726 \mathrm{X}$

published online 8.6.2021

(c) 2021. Thieme. All rights reserved.

Georg Thieme Verlag KG, Rüdigerstraße 14,

70469 Stuttgart, Germany

\section{ENDOSCOPY E-VIDEOS}

https://eref.thieme.de/e-videos

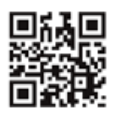

Endoscopy E-Videos is an open access online section, reporting on interesting cases and new techniques in gastroenterological endoscopy. All papers include a high quality video and all contributions are freely accessible online. Processing charges apply (currently EUR 375), discounts and wavers acc. to HINARI are available.

This section has its own submission website at https://mc.manuscriptcentral.com/e-videos 